\title{
A Research on Modification Method for NSM FRP-Concrete Bonded Joints Strength Models
}

\author{
Jing Li, ${ }^{1}$ Liwen Zhang ${ }^{D},{ }^{1}$ Yanggui Deng, ${ }^{2}$ and Junping Zhang ${ }^{1}$ \\ ${ }^{1}$ Department of Civil Engineering, Guangzhou University, Guangzhou, China \\ ${ }^{2}$ Zhongdu Engineering Design Co., Ltd., Guangzhou, China \\ Correspondence should be addressed to Liwen Zhang; lwzhang@gzhu.edu.cn
}

Received 7 November 2019; Accepted 17 January 2020; Published 12 March 2020

Guest Editor: Tianyu Xie

Copyright (c) 2020 Jing Li et al. This is an open access article distributed under the Creative Commons Attribution License, which permits unrestricted use, distribution, and reproduction in any medium, provided the original work is properly cited.

A modification method was proposed for near-surface mounted (NSM) fiber-reinforced polymer (FRP)-concrete bonded joints strength prediction models considering model uncertainty. A database consisting of 246 test records was involved. Three bonded joints strength prediction models for NSM FRP reinforcement system were selected for modification. All the three selected models have model uncertainty factors associated with input design parameters. Spearman correlation analysis was used to prove the systematic correlation of the model uncertainty factors. For each model, a regression function $f$ was established to eliminate the systematic nonrandom part of the model uncertainty factor. Then, the model uncertainty factors could be described by random variables obeying logarithmic normal distribution. A reliability analysis using the JC method was carried out to validate the practical significance and value of model modification. This study improves the predictability of FRP NSM reinforcement systems and provides valuable references for model calibration in practical engineering.

\section{Introduction}

As one of the most effective techniques for the strengthening of aged concrete structures $[1,2]$, near-surface mounted (NSM) reinforcement involves inserting a reinforcing material into the concrete cover of the structural member which needs to be reinforced. In the past decade, researchers have been working on various studies of the NSM FRP reinforcement techniques, promoting its widespread application [3, 4]. For FRP NSM reinforcement systems, the utilization of FRP's mechanical properties and reinforcement effects depends mainly upon their bonded joints strength [5-7].

Some prediction models have been proposed for NSM FRP-concrete bonded joints strength [2, 8-11]. Model uncertainty inevitably exists due to limited experimental data, incomplete research parameters, and idealized calculation methods, resulting in a certain error between the predicted value and the experimental value. From the perspective of engineering application, the calculated strength less than the measured value is regarded to be conservative, while the opposite is unsafe [12]. At present, the study on how to calibrate existing NSM FRP-concrete bonded joints strength models is still insufficient, unsystematic, and superficial, requiring relative further research [13-16]. Thus, our study is aimed at proposing a calibrating method for commonly used NSM FRP-concrete bonded joints strength models with the consideration of model uncertainty.

A model uncertainty factor was defined and adopted to quantitatively describe the model uncertainty [17]. The key is that this model uncertainty factor must be "random" and should have no dependence on the input design parameters [18]. For some NSM FRP-concrete bonded joints strength prediction models, the model uncertainty factor has a dependency on the design parameters, which does not match the definition. Hence, a regression analysis is needed to eliminate the systematic part from the model uncertainty factor, and the randomness of regression residual needs to be verified.

In this paper, a total of 246 effective NSM FRP pullout test data were gathered. Three NSM FRP-concrete bonded 
joints strength models presented by Seracino et al. [19-21], which were confirmed to have model uncertainties, were incorporated for model calibration. The systematic effect on the model uncertainty factor was eliminated by carrying out a multiple regression analysis. The residual part was checked for randomness, and three modified models were obtained. This research can improve the prediction precision of NSM FRP reinforcement systems and provide valuable references for model calibration in practical engineering.

\section{Bonded Joints Strength Models}

A number of prediction models have been applied to calculate the NSM FRP-concrete bonded joints strength. Three commonly used NSM FRP-concrete bond stress models with model uncertainty were incorporated in this paper. They were proposed by Seracino et al. [16], Ali et al. [20], and Zhang et al. [21] as listed in Table 1 and were abbreviated as SR Model, AM Model, and Zhang Model hereinafter. In this paper, the bonded joints strength was defined as the maximum load in a pullout test [22]. Hence, for the three selected bonded joints stress models, peak loads (bonded joints strength) were calculated according to the bonded joints strength model presented by Seracino et al. [19], as shown in the fifth row in Table 1 . In this table, $\tau_{\max }$ is the peak bond stress, $f_{c}$ is the concrete compression strength, $b_{p}$ is the width of groove, $t_{p}$ is the height of FRP, $\gamma$ is the height-to-width ratio of groove, $\varphi_{f}$ is the length-to-width ratio of failure surface, $P_{\text {IC }}$ is the peak bond load, $\delta_{\max }$ is the maximum bond slip, $L_{\text {per }}$ is the perimeter of failure surface, and $(E A)_{P}$ is the stiffness of FRP.

\section{Experimental Data}

Research shows that the bonded joints strength of a FRP NSM reinforcement system is concerned with a variety of factors, e.g., physical dimension and material property [23]. However, it is impractical to take all relevant factors into account [24]. In this paper, five significant influence parameters were selected as the key factors: (1) concrete compression strength $f_{\mathcal{c}}$, (2) FRP modulus of elasticity $E_{f},(3)$ FRP height $t_{p}$, (4) FRP thickness $t_{f}$, and (5) groove width $t_{g}$ [25].

A database covering all the five selected key factors and the related bonded joints strength was collected for analysis $[26,27]$. Five typical failure modes, occurring on three intermediate materials (FRP, adhesive, and concrete) as well as two interfaces (adhesive-concrete and adhesive-FRP), were incorporated into this paper. According to the critical region where failure may occur, they were, respectively, failures in the interface of concrete and adhesive, in the interface of adhesive and FRP, within the adhesive, in a single material (concrete crushing or FRP rupture), and in the surface of concrete (cracks propagate through the concrete). Of particular note is that this study only took pullout tests into account instead of bending tests here [28]. Because the bonded joints strength of a FRP NSM reinforcement system is normally evaluated by a pullout test.
TABLE 1: Selected bonded joints strength models.

\begin{tabular}{lc}
\hline Reference & Model \\
\hline Ali et al. [20] & $\tau_{\max }=0.54 \sqrt{f_{c}} b_{p}^{0.4} t_{p}^{0.3}$ \\
Zhang et al. [21] & $\tau_{\max }=1.15 \gamma^{0.138} f_{c}^{0.613}$ \\
Seracino et al. [16] & $\tau_{\max }=\left(0.802+0.078 \varphi_{f}^{0.526}\right) f_{c}^{0.6}$ \\
Seracino et al. [19] & $P_{\text {IC }}=\sqrt{\tau_{\max } \delta_{\max }} \sqrt{L_{\mathrm{per}}(E A)_{P}}$ \\
\hline
\end{tabular}

A total of 246 test data were collected and divided into five sets in terms of their failure modes (as shown in Tables 2-6). As for the fiber type, 5 different fiber were involved, such as carbon FRP (CFRP), aramid FRP (AFRP), glass FRP (GFRP), basalt FRP (BFRP), and graphite FRP.

\section{Model Uncertainty Factor}

Model uncertainty inevitably exists due to varying degrees of idealization involved in calculation methods. The error between the predicted strength and the experimental value was described by a model uncertainty factor, which can be defined by the following formula $[38,39]$ :

$$
P_{u}^{m}=\varepsilon \times P_{u}^{c}
$$

$P_{u}^{m}$ herein is the actual measuring bonded joints strength, $P_{u}^{c}$ is the calculated prediction value, and $\varepsilon$ is the model uncertainty factor which can quantitatively evaluate the impact of model uncertainty on the structure. A model uncertainty factor greater than 1 means that the measured value is larger than the calculated strength, and vice versa. Theoretically, the best value of $\varepsilon$ is 1.0 ; therefore, the value getting closer to 1.0 suggests a more accurate model. The coefficient of variance $(\mathrm{CV})$ of $\varepsilon$ indicates the dispersion degree of prediction models. The smaller the CV of $\varepsilon$ is, the higher the accuracy of the model is.

Practically, $\varepsilon$ greater than 1 is regarded to be conservative, while the opposite is unsafe. On the basis of the collected pullout test data, the $P_{u}^{c}$ under different failure modes could be calculated. Then, the model uncertainty factor $\varepsilon$ could be obtained according to equation (1).

Figures $1-5$ plot the contrast between the calculated value $P_{u}^{c}$ (vertical axis) and the experimental value $P_{u}^{m}$ (horizontal axis) for the three models under five failure modes. If the data points are tightly distributed near the 45-degree line, the model is considered to be accurate. Conversely, the model has a great dispersion. As shown in Figures 1-5, for the three models under the five failure modes, their data points are not distributed near the 45-degree line, indicating that these three models are very discrete.

Tables 7-11 display the statistics of calculated $\varepsilon$ under five failure modes, including their mean value, the standard deviation (SD), and the coefficient of variation (CV). The tables below have shown the $\mathrm{CV}$ of $\varepsilon$ ranging from 0.4 (the AM Model and Zhang Model under adhesive failure mode) to 0.61 (the three models under adhesive-concrete interface failure mode). However, the $\mathrm{CV}$ of a model uncertainty factor ranging from 0.2 to 0.3 is usually considered to be reasonable [40]. 
TABLE 2: Database under the adhesive-concrete interface failure mode.

\begin{tabular}{|c|c|c|c|c|c|c|c|}
\hline Reference & Tests number & Material & $f_{c}(\mathrm{MPa})$ & $E_{f}(\mathrm{GPa})$ & $t_{p}(\mathrm{~mm})$ & $t_{f}(\mathrm{~mm})$ & $t_{g}(\mathrm{~mm})$ \\
\hline [13] & 16 & CFRP/GFRP & 22 & $37.17-174.17$ & $8-11.3$ & $8-11.3$ & $10-24$ \\
\hline [24] & 6 & CFRP & 34.5 & 124 & 12 & 12 & $20-25$ \\
\hline [29] & 13 & BFRP/GFRP/CFRP & 19 & $46-182$ & $6-15$ & $1.4-10$ & $5-15$ \\
\hline [30] & 28 & BFRP/GFRP/CFRP & 19 & $42-182$ & $6-15$ & $2.5-10$ & $8-20$ \\
\hline [31] & 11 & BFRP/GFRP/CFRP & $19.6-49.3$ & $51-177$ & $6-15$ & $1.4-8$ & $5-15$ \\
\hline [32] & 15 & CFRP & 34 & $124-210$ & 12 & 12 & 20 \\
\hline Total & 89 & BFRP/GFRP/CFRP & $19-49.3$ & $37.17-210$ & $6-15$ & $1.4-12$ & $5-25$ \\
\hline
\end{tabular}

TABle 3: Database under the adhesive-FRP interface failure mode.

\begin{tabular}{|c|c|c|c|c|c|c|c|}
\hline Reference & Number of tests & FRP material & $f_{c}(\mathrm{MPa})$ & $E_{f}(\mathrm{GPa})$ & $t_{p}(\mathrm{~mm})$ & $t_{f}(\mathrm{~mm})$ & $t_{g}(\mathrm{~mm})$ \\
\hline$[33]$ & 3 & CFRP & 36.199 & $37.17-174.17$ & 11 & 11 & 14 \\
\hline$[24]$ & 2 & CFRP & 34.5 & 124 & 12 & 12 & 25 \\
\hline [29] & 7 & GFRP/CFRP & 19 & $46-182$ & 8 & 8 & $14-15$ \\
\hline [30] & 4 & GFRP/CFRP & 19 & $51-159$ & $8-10$ & $8-10$ & $14-15$ \\
\hline$[34]$ & 6 & BFRP/GFRP/CFRP & 36.2 & $40.8-155$ & $6-10$ & $6-10$ & $5-15$ \\
\hline [35] & 6 & CFRP & 34.86 & $124-165$ & $8-20$ & $1.4-8$ & $6-20$ \\
\hline$[31]$ & 1 & CFRP & 19.6 & 155 & 8 & 8 & 14 \\
\hline$[36]$ & 2 & CFRP & 28.5 & $149-155$ & 9.5 & 9.5 & $14.25-19$ \\
\hline Total & 31 & BFRP/GFRP/CFRP & $19-36.2$ & $37.17-182$ & $6-20$ & $1.4-12$ & $5-25$ \\
\hline
\end{tabular}

TABle 4: Database under the adhesive failure mode.

\begin{tabular}{lccccccc}
\hline Reference & Number of tests & FRP material & $f_{c}(\mathrm{MPa})$ & $E_{f}(\mathrm{GPa})$ & $t_{p}(\mathrm{~mm})$ & $t_{f}(\mathrm{~mm})$ & $t_{g}(\mathrm{~mm})$ \\
\hline$[13]$ & 2 & CFRP & 22 & 37.17 & 11 & 11 \\
{$[31]$} & 9 & BFRP/GFRP/CFRP & $19.6-49.3$ & $46-182$ & $6-15$ & $2.5-8$ \\
{$[36]$} & GFRP/CFRP & 28.5 & $41-155$ & $7.5-16$ & $4.5-10$ \\
{$[37]$} & 16 & GFRP/CFRP & 41 & $42-139$ & $9.5-12.7$ & $9.5-12.7$ & $14.25-25.4$ \\
{$[6]$} & 13 & CFRP & $34-65.7$ & 146 & 12 & 12 \\
{$[16]$} & 2 & GFRP & $33.4-49.2$ & $161.8-162.3$ & $14.9-20.37$ & $1.26-1.28$ & $3.26-3.27$ \\
Total & 3 & BFRP/GFRP/CFRP & $19-65.7$ & $37.17-182$ & $6-20.37$ & $1.26-12.7$ & $3.26-25.4$ \\
\hline
\end{tabular}

TABLe 5: Database under the concrete crush or FRP rupture failure mode.

\begin{tabular}{lccccccc}
\hline Reference & Number of tests & FRP material & $f_{c}(\mathrm{MPa})$ & $E_{f}(\mathrm{GPa})$ & $t_{p}(\mathrm{~mm})$ & $t_{f}(\mathrm{~mm})$ & $t_{g}(\mathrm{~mm})$ \\
\hline$[33]$ & 4 & CFRP & $34.47-36.199$ & 227.54 & 11 & 11 \\
{$[16]$} & 10 & GFRP & $33.4-53$ & $161.8-162.3$ & $10.1-20.47$ & $1.24-1.28$ & $3.24-3.28$ \\
{$[29]$} & 4 & BFRP/CFRP & 19 & $46-177$ & $6-10$ & $1.4-6$ \\
{$[30]$} & 4 & BFRP/CFRP & 19 & $46-177$ & $6-10$ & $1.4-6$ & $5-10$ \\
{$[37]$} & 8 & CFRP/GFRP & 41 & $43.5-128$ & $9.5-12.7$ & $9.5-12.7$ & $14.25-25.4$ \\
{$[6]$} & 4 & CFRP & $34-65.7$ & 146 & 12 & 12 & 30 \\
{$[31]$} & 4 & CFRP/GFRP/BFRP & 29.7 & $48-180$ & $8-10$ & $8-10$ & $13-15$ \\
Total & 38 & CFRP/GFRP/BFRP & $19-65.7$ & $43.5-227.54$ & $6-20.47$ & $1.24-12.7$ & $3.24-30$ \\
\hline
\end{tabular}

TABLE 6: Database under the concrete surface failure mode.

\begin{tabular}{|c|c|c|c|c|c|c|c|}
\hline Reference & Number of tests & FRP material & $f_{c}(\mathrm{MPa})$ & $E_{f}(\mathrm{GPa})$ & $t_{p}(\mathrm{~mm})$ & $t_{f}(\mathrm{~mm})$ & $t_{g}(\mathrm{~mm})$ \\
\hline [16] & 12 & CFRP & 38.8 & $140-170$ & 10 & $3.6-6$ & 20 \\
\hline [19] & 9 & GFRP & $30-64.8$ & $144.6-162.3$ & $9.95-20.23$ & $1.2-2.97$ & $3.26-3.27$ \\
\hline Total & 33 & CFRP/GFRP & $30-64.8$ & $140-170$ & $9.95-20.23$ & $1.2-6$ & $3.26-20$ \\
\hline
\end{tabular}

Therefore, for the models with quite high $\mathrm{CV}$, such as the three models under the adhesive-concrete interface failure mode with a CV of 0.61 as listed in Table 7 , a further investigation into the systematic reason which causes a large prediction deviation was required [41]. That is to say, the model uncertainty factor $\varepsilon$ directly calculated 


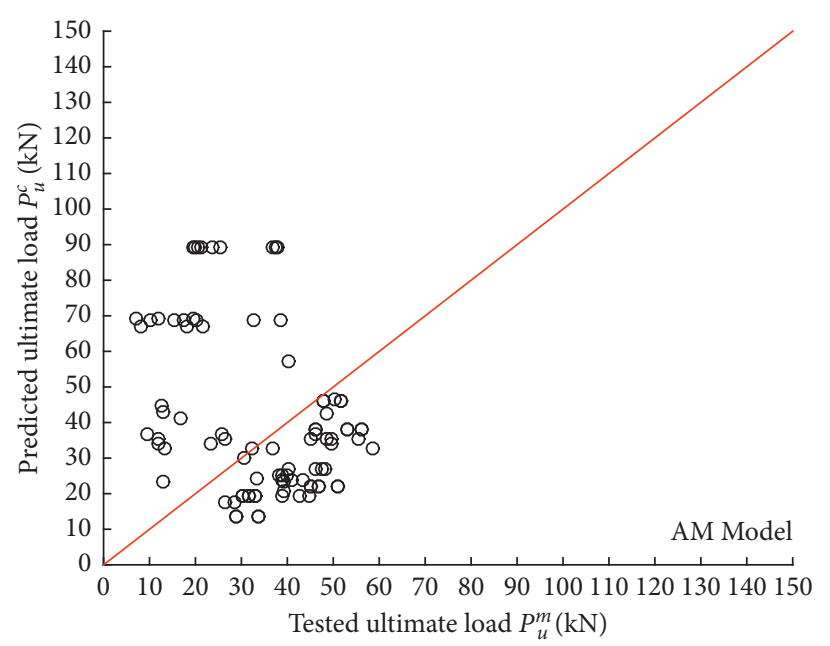

(a)

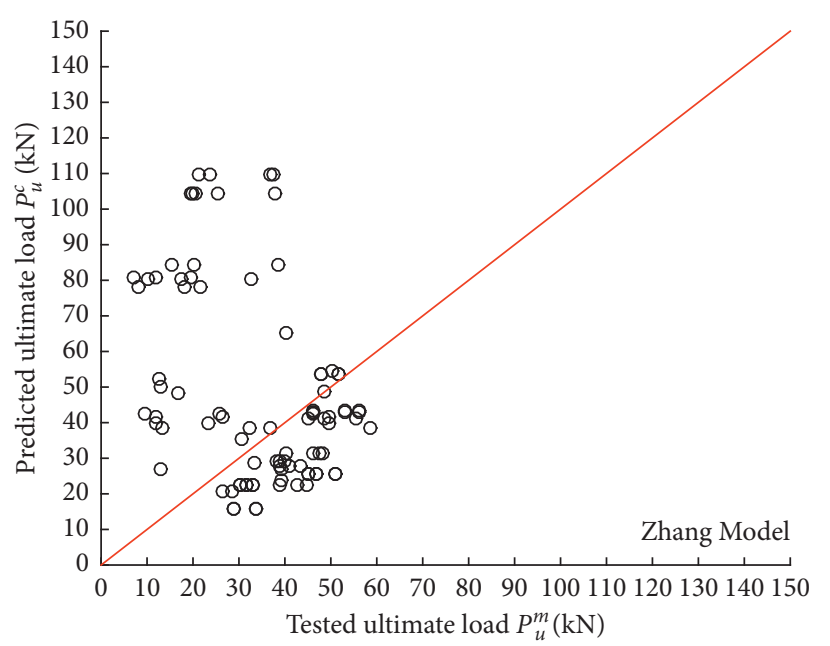

(b)

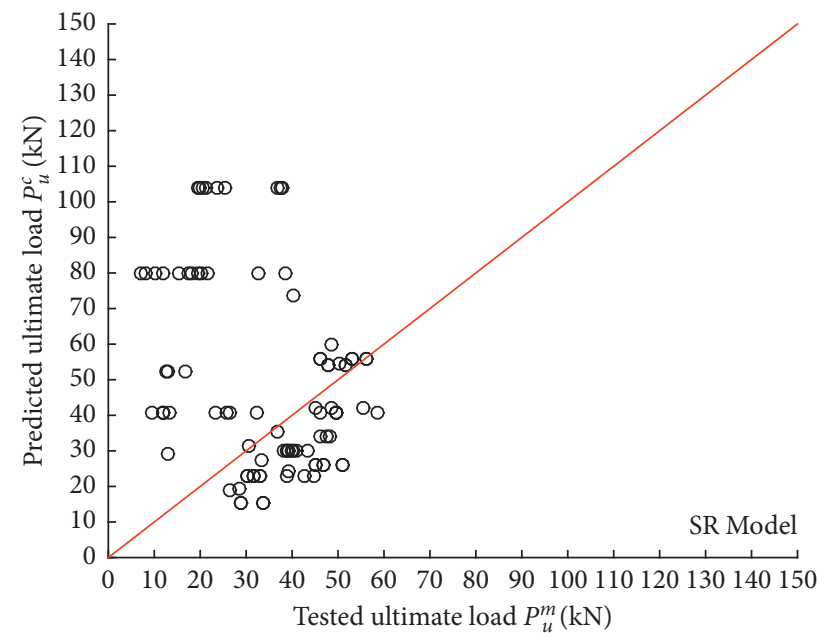

(c)

Figure 1: Comparison between the calculated value and the experimental value for the three models under the adhesive-concrete interface failure mode: (a) AM Model, (b) Zhang Model, and (c) SR Model.

by equation (1) was necessary to be checked for randomness.

Take the AM Model as an example, a scatter plot of the model uncertainty factor (written as $\varepsilon_{\mathrm{AM}}$ ) against the concrete compression strength $f_{c}$ is shown in Figure 6, where an obvious nonlinear relationship existed, indicating that the model uncertainty factor $\varepsilon$ calculated by equation (1) was not a random variable but with an obvious dependence upon the design parameters, i.e., the concrete compression strength $f_{c}$ in this case.

In order to clarify whether the model uncertainty factor is systematically dependent on the design parameters, a correlation analysis is needed.

In this paper, the distribution of the model uncertainty factor is featured by uncertainty. Hence, the Spearman correlation coefficient method, which has no specific requirements on the distribution characteristics of the data, was adopted to perform a correlation analysis for the model uncertainty factor and the five input parameters.
When the significance level ( $p$ value) is larger than 0.05 , the Spearman correlation coefficient method is a nonparametric test with a null hypothesis of zero-rank correlation. In a Spearman correlation analysis, a customary significance value is larger than 0.05 , and the absolute value of $r$ close to 1.0 means high dependence. The Spearman correlation analysis showed that there was a negative correlation between $\varepsilon_{\mathrm{AM}}$ and the design parameters, with a high level of $r$-value ranging from -0.450 to -0.728 and a low level of $p$ value ranging from 0.001 to 0.013 (see the second and fourth columns in Table 12). It statistically demonstrated that the model uncertainty factor $\varepsilon_{\mathrm{AM}}$ was systematically dependent on the five input parameters.

Similarly, Spearman correlation analysis was performed for Zhang Model and SR Model, respectively. The results indicated that the uncertainty factors of all the three models were statistically dependent upon the design parameters. Therefore, a further analysis for the dependency was necessary. 


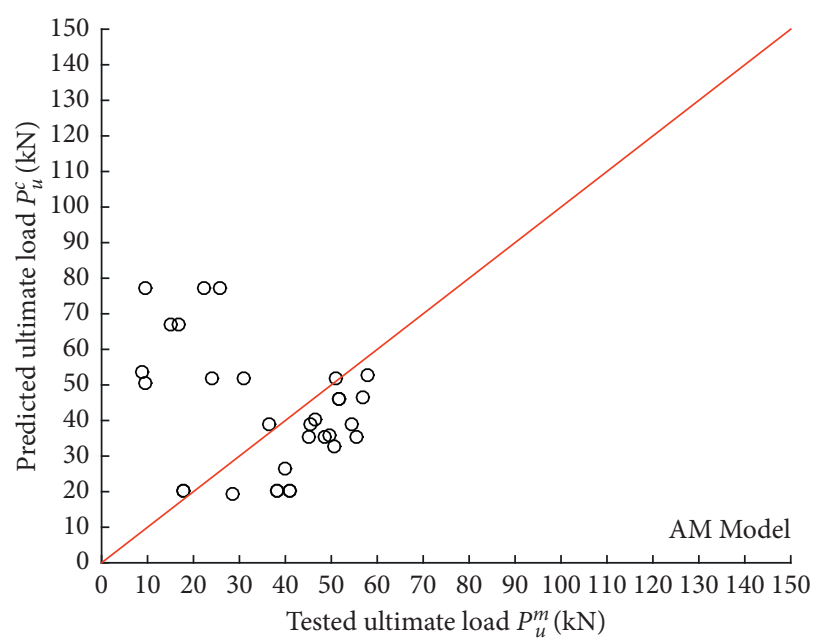

(a)

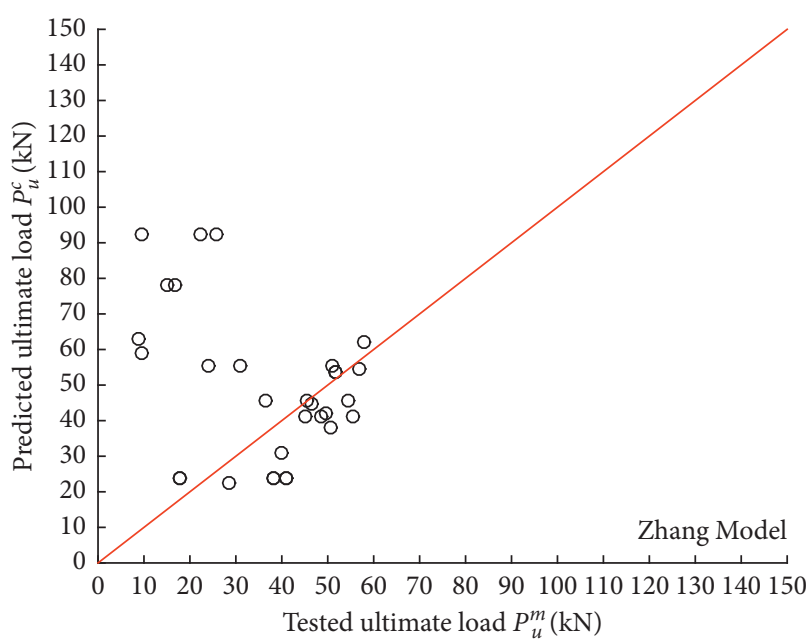

(b)

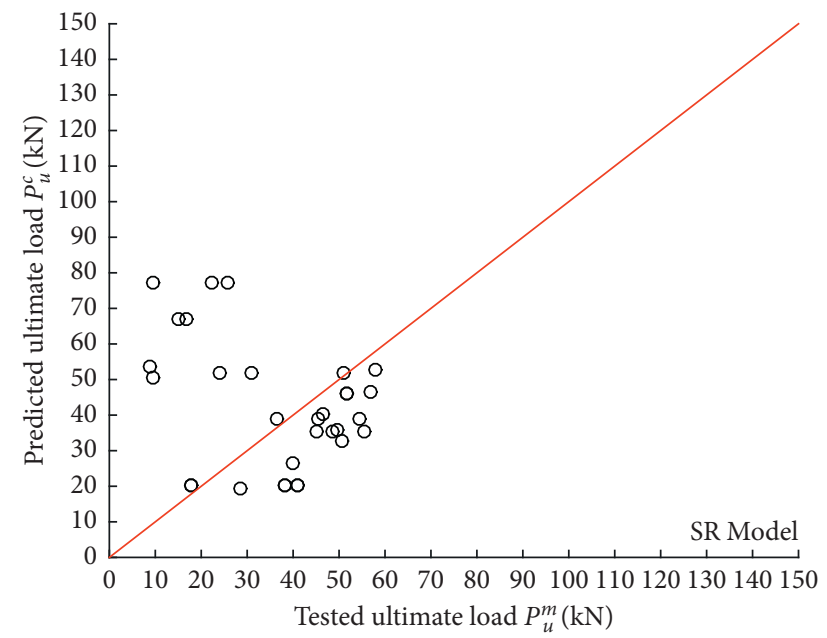

(c)

FIgure 2: Comparison between the calculated value and the experimental value for the three models under the adhesive-FRP interface failure mode: (a) AM Model, (b) Zhang Model, and (c) SR Model.

By definition, since the model uncertainty factor must be a random variable with no dependency on the design parameters, a multiple regression analysis should be performed to eliminate the correlation between the model uncertainty factor and the design parameters, which is resulted from the systematic correlation part.

The residual random factor (represented by $\varepsilon^{*}$ ) could be obtained by eliminating the systematic dependence (expressed by a multiple regression function $f$ ). That is, the model uncertainty factor $\varepsilon$ can be regarded as a composition of a systematic correlation part $f$ and a residual random factor $\varepsilon^{*}$ :

$$
\varepsilon=f \times \varepsilon^{*} .
$$

Substituting equation (2) into equation (1), equation (1) then turns into

$$
P_{u}^{m}=\varepsilon^{*} \times f \times P_{u}^{c} .
$$

Since the CV of the three selected models was high, the model uncertainty factor was then characterized by reducing the $\mathrm{CV}$. Subsequently, a proper regression function $f$ was built and the residual random factor $\varepsilon^{*}$ was characterized. Thus, $\varepsilon^{*}$ was defined as the updated model uncertainty factor.

\section{Model Modification}

Regression analysis can explain the relationship between the model uncertainty factor and the design parameters by a regression equation which was established by collecting data points from test results. Then, the randomness of the model uncertainty factor and the precision of the regression equation were checked by the rest data points. In this study, all the three selected models under the five failure modes were calibrated, but only the AM Model under the adhesiveconcrete interface failure mode was discussed in detail. In total, 89 data points have been collected for AM Model under adhesive-concrete interface failure mode (as shown in Table 2). 59 data points were used to establish the regression equation, and the rest 30 data points were used to check for randomness. 


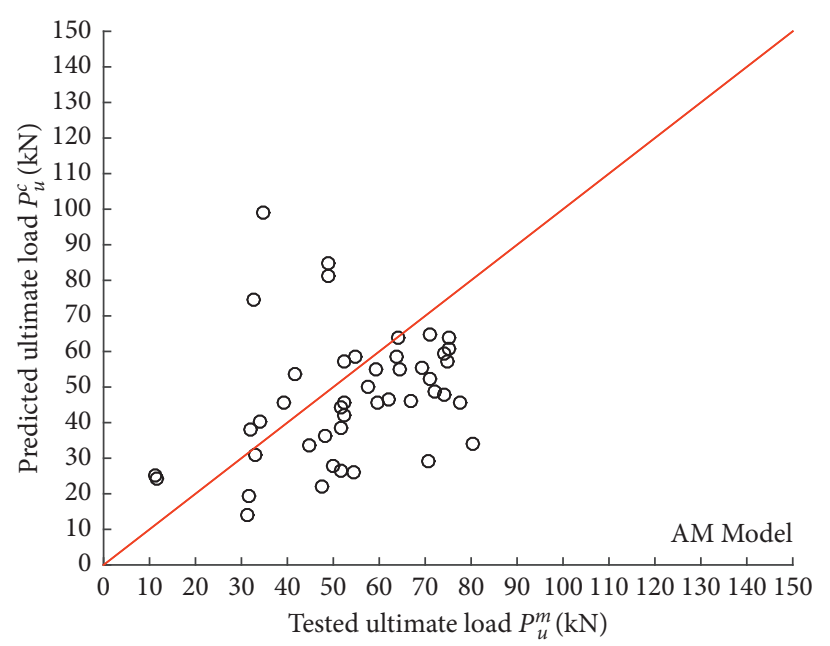

(a)

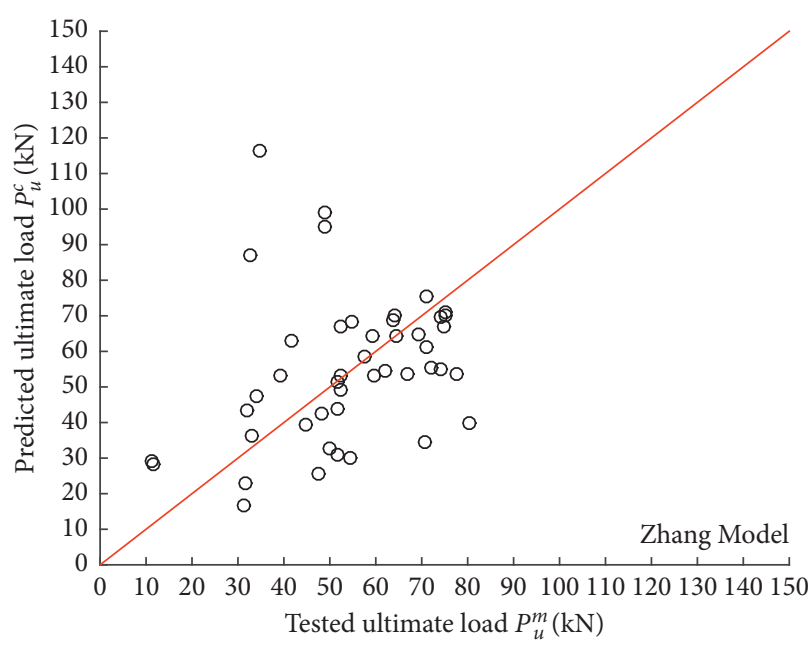

(b)

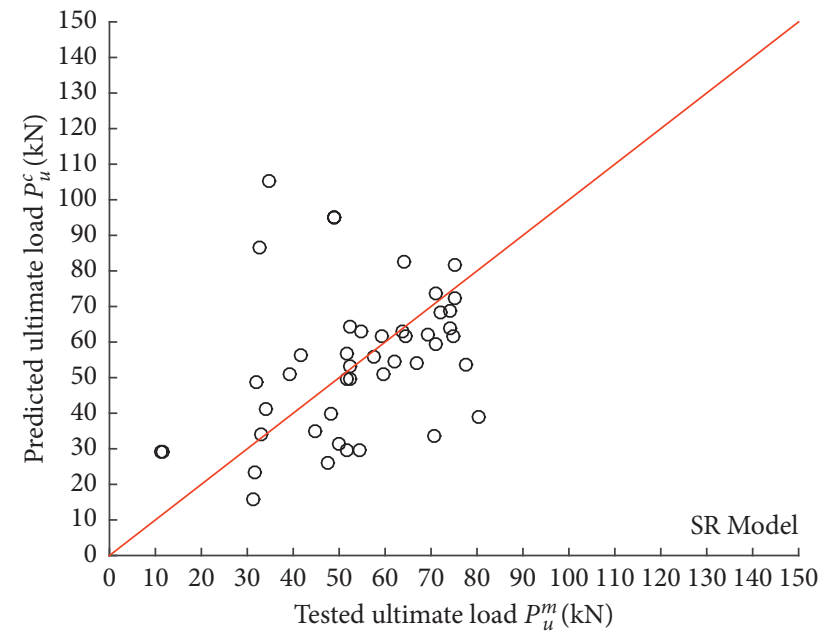

(c)

Figure 3: Comparison between the calculated value and the experimental value for the three models under the adhesive failure mode: (a) AM Model, (b) Zhang Model, and (c) SR Model.

The multiple regression analysis included two steps. In step one, the form of a correlation function (i.e., core function) was determined. The relationship between the model uncertainty factor and the design parameters can be expressed by the core function. The concerned functional relation equation was fitted by a MATLAB program written according to the damped LM algorithm [42, 43], and the calculated model uncertainty factors $\varepsilon$ were plotted against the specific parameters by scatter plots in Figure 7.

The fitting function graphs show that the relation between the model uncertainty factor $\varepsilon$ and each of the five design parameters was obviously nonlinear. The nonlinear trends with respect to the concrete compression strength $f_{c}$ and the FRP height $t_{p}$ were quite significant as shown in Figures $7(\mathrm{a})$ and $7(\mathrm{c})$. It can be noticed that the variation of $\varepsilon$ with $f_{c}$ and $t_{p}$ can be more accurately fitted by a power function and an exponential function, respectively. For consistency reason, the exponential function and the power function were also adopted to fit the variation of $\varepsilon$ with the other three input parameters. Then, the core functions for the five input parameters can be gained as follows:

$$
\begin{aligned}
& \varepsilon \propto f_{c}^{b_{1}}, \\
& \varepsilon \propto E_{f}^{b_{2}}, \\
& \varepsilon \propto e^{b_{3} t_{p}}, \\
& \varepsilon \propto e^{b_{4} t_{f}}, \\
& \varepsilon \propto e^{b_{5} t_{g}}
\end{aligned}
$$

where $b_{i}$ is the regression coefficient. It must be noted that the regression coefficient $b_{i}$ for each of the five core functions was still undetermined in the first step of regression. This is because the influence effect arising from the other four input parameters was represented by each $b_{i}$ in the five equations above. 


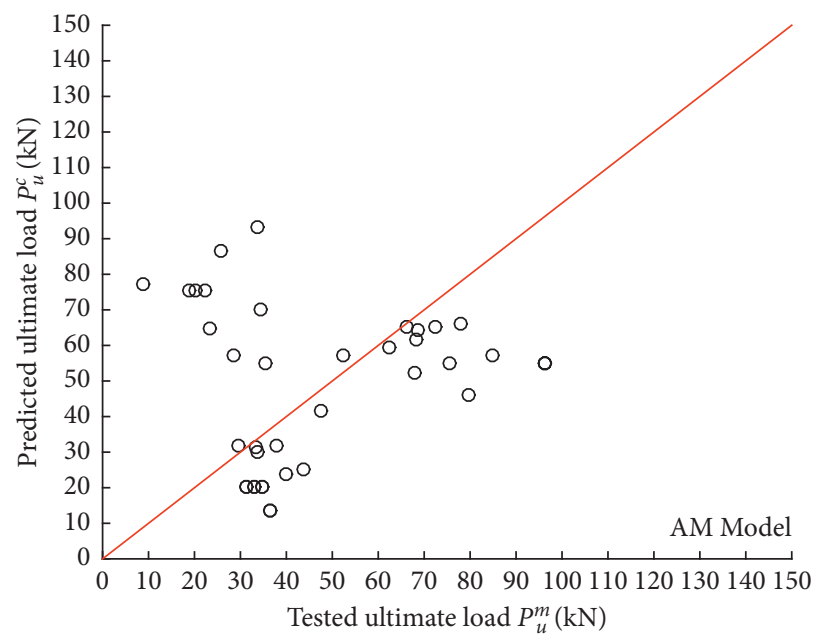

(a)

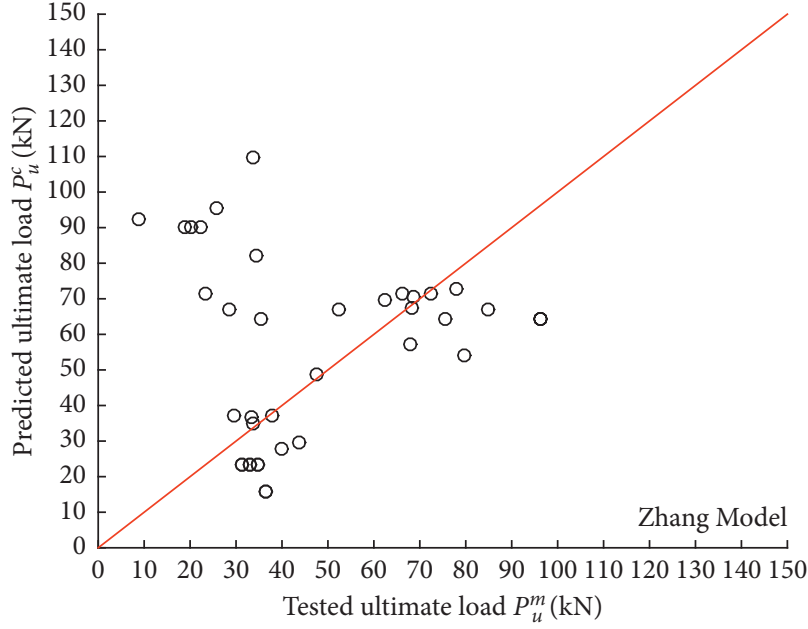

(b)

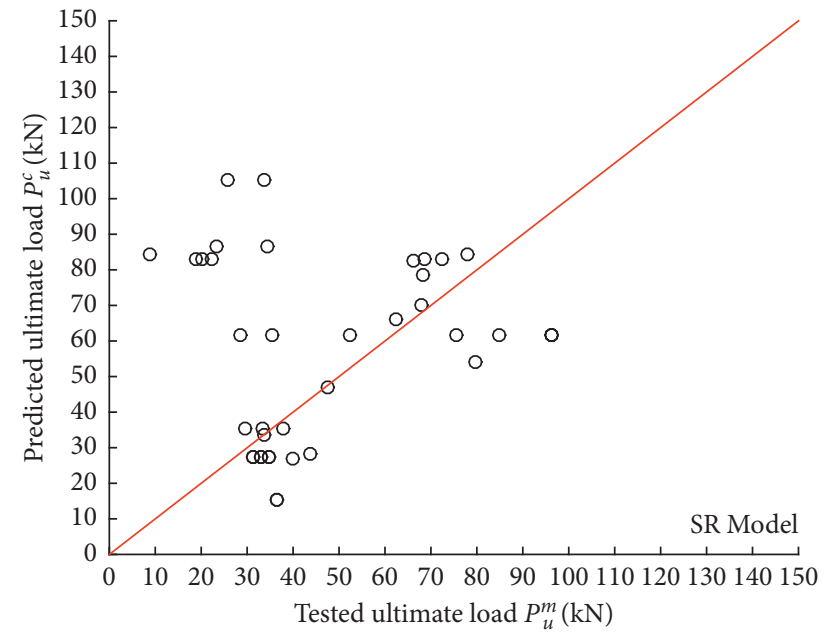

(c)

FIGURE 4: Comparison between the calculated value and the experimental value for the three models under concrete crush or FRP rupture failure mode: (a) AM Model, (b) Zhang Model, and (c) SR Model.

In the second step of regression, five core functions were combined together to constitute a multiplicative model $f$. Therefore, a regression function $f$ was generated to multiplicatively describe the systematic dependence of the uncertainty factor on the five design parameters as follows:

$$
f=e^{b_{0}} * e^{b_{1} \ln f_{c}} * e^{b_{2} \ln E_{f}} * e^{b_{3} t_{p}} * e^{b_{4} t_{f}} * e^{b_{5} t_{g}}
$$

where $b_{i}$ herein is the coefficient of the regression equation $f$. The model uncertainty factor can be given as follows:

$$
\varepsilon=f * \varepsilon^{*}=e^{b_{0}} * e^{b_{1} \ln f_{c}} * e^{b_{2} \ln E_{f}} * e^{b_{3} t_{p}} * e^{b_{4} t_{f}} * e^{b_{5} t_{g}} * \varepsilon^{*} .
$$

$\varepsilon^{*}$ herein is the residual random factor, obtained by removing the correlation function $f$ from the model uncertainty factor $\varepsilon$. The regression function can be transformed from a product form into a summation form through a logarithmic transformation on the two sides of equation (5). So the multiple nonlinear regression analysis can be mathematically reduced to a multiple linear regression analysis.

The least square method was used to determine the five regression coefficients $b_{i}$. In our paper, a multiple linear regression analysis was carried out using SPSS to determine all the coefficients $b_{i}$ as listed in Table 13 . It can be seen from the table that each of the three models has a high determination of coefficient $R^{2}$ (0.854 for the AM Model, 0.858 for the Zhang Model, and 0.840 for the SR Model).

According to the regression principles, the residual $\varepsilon^{*}$ is a random variable with no dependence on the design parameters. However, it is necessary to check the residual $\varepsilon^{*}$ for randomness by using a new set of test data. Hence, the remaining 30 data points were adopted here for the randomness verification.

With the AM Model as example, the results of Spearman correlation analysis are shown in Table 12, including the correlation coefficient $r$ and the significance $p$ value before and after the modification. The dependency of the model 


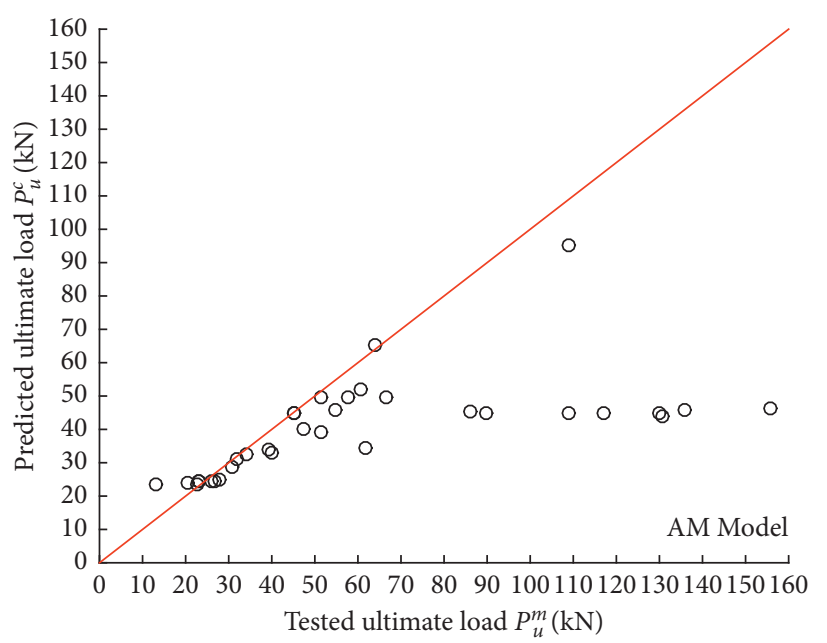

(a)

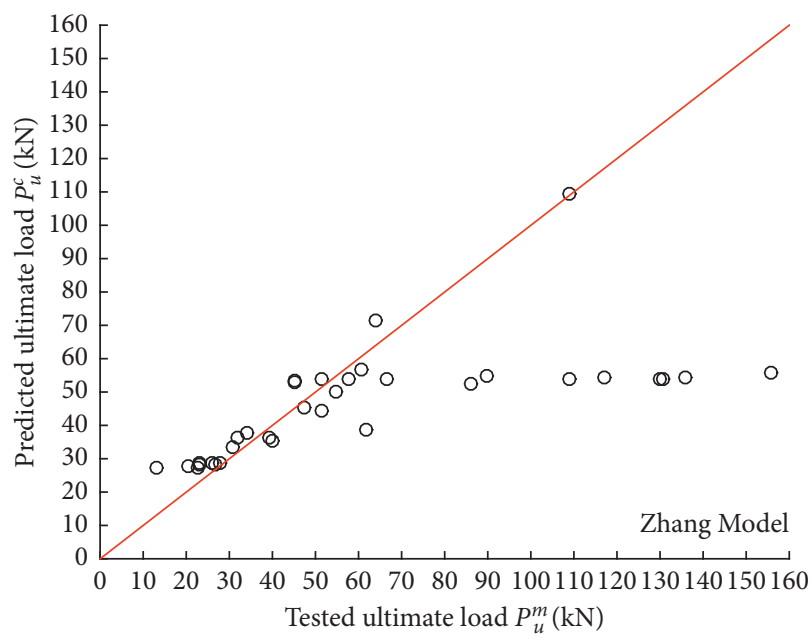

(b)

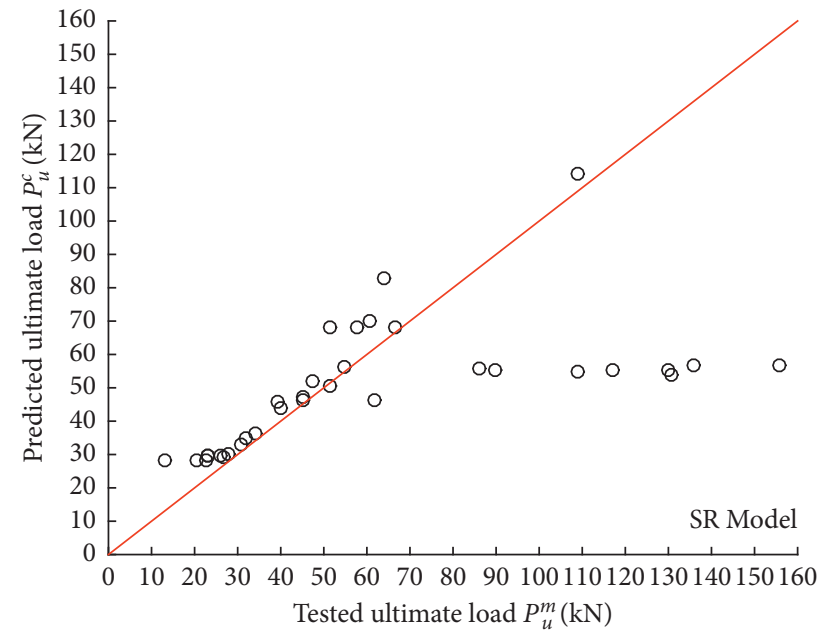

(c)

Figure 5: Comparison between the calculated value and the experimental value for the three models under concrete surface failure mode: (a) AM Model, (b) Zhang Model, and (c) SR Model.

TABLE 7: The statistics of calculated $\varepsilon$ under adhesive-concrete interface failure mode.

\begin{tabular}{lccc}
\hline Model & Mean & SD & CV \\
\hline AM Model & 1.17 & 0.7 & 0.61 \\
Zhang Model & 0.99 & 0.61 & 0.61 \\
SR Model & 0.96 & 0.59 & 0.61 \\
\hline
\end{tabular}

uncertainty factor on the five input parameters was statistically proved to be sharply reduced. Thus, the residual factor $\varepsilon^{*}$ can be regarded as a random part of $\varepsilon$.

Figure 8 plots the histogram of the residual part $\varepsilon^{*}$ for each of the three modified models. As seen from the figure, for the three modified models, the mean value of $\varepsilon^{*}$ was about 1.06 , which was obviously closer to 1.00 in contrast to the original mean value of $\varepsilon$. Moreover, a mean value a little greater than 1.00 is regarded to be conservative and acceptable. Besides, for all the three models, the CV values of $\varepsilon^{*}$ were markedly decreased to an acceptable 0.3 , fully
TABLE 8: The statistics of calculated $\varepsilon$ under adhesive-FRP interface failure mode.

\begin{tabular}{lccc}
\hline Model & Mean & SD & CV \\
\hline AM Model & 1.05 & 0.58 & 0.55 \\
Zhang Model & 0.90 & 0.49 & 0.55 \\
SR Model & 1.05 & 0.58 & 0.55 \\
\hline
\end{tabular}

demonstrating that the systematic correlation has been effectively eliminated by regression. Now, those three models' uncertainty factors have been adequately characterized.

The determined systematic correlation function $f$ can be used for model modification, as shown below:

$$
P_{u}^{c^{\prime}}=f * P_{u}^{c} .
$$

$P_{u}^{c^{\prime}}$ herein is the predicted bonded joints strength after modification. The residual factor $\varepsilon^{*}$, a random variable, can 
TABLE 9: The statistics of calculated $\varepsilon$ under adhesive failure mode.

\begin{tabular}{lccc}
\hline Model & Mean & SD & CV \\
\hline AM Model & 1.25 & 0.5 & 0.4 \\
Zhang Model & 1.08 & 0.43 & 0.4 \\
SR Model & 1.08 & 0.44 & 0.41 \\
\hline
\end{tabular}

TABLE 10: The statistics of calculated $\varepsilon$ under concrete crush or FRP rupture failure mode.

\begin{tabular}{lccc}
\hline Model & Mean & SD & CV \\
\hline AM Model & 1.47 & 0.74 & 0.5 \\
Zhang Model & 1.26 & 0.6 & 0.48 \\
SR Model & 1.19 & 0.6 & 0.50 \\
\hline
\end{tabular}

TABLE 11: The statistics of calculated $\varepsilon$ under concrete surface failure mode.

\begin{tabular}{lccc}
\hline Model & Mean & SD & CV \\
\hline AM Model & 1.17 & 0.62 & 0.53 \\
Zhang Model & 1.01 & 0.54 & 0.53 \\
SR Model & 0.98 & 0.54 & 0.55 \\
\hline
\end{tabular}

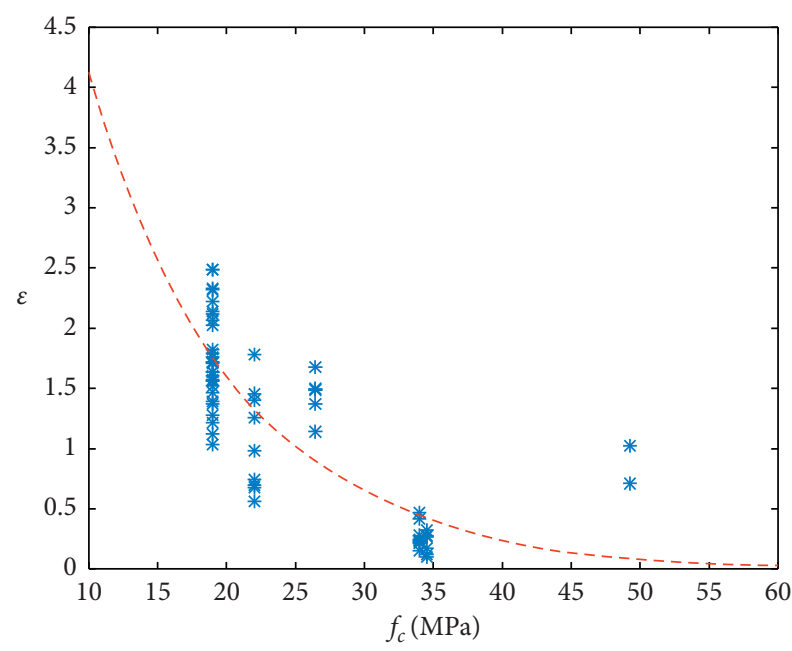

FIgURe 6: The model uncertainty factor $\varepsilon$ against concrete compression strength $f_{c}$ (AM Model).

then be regarded as the new model uncertainty factor for modified prediction models:

$$
P_{u}^{m}=\varepsilon^{*} * P_{u}^{c^{\prime}} .
$$

For all the three models, the comparison between the modified calculated value $P_{u}^{c^{\prime}}$ and the measured value $P_{u}^{m}$ was replotted (Figures 9(a)-9(c)). It is observed that all the modified data points are distributed near the 45 -degree line after eliminating the systematic correlation.

In contrast with the original data (Figures $1(a)-1(c)$ ), the difference between the calculated strength and the test value has been reduced significantly.
TABLE 12: Check for the randomness of the model uncertainty factor (AM Model).

\begin{tabular}{lcccc}
\hline Design parameter & \multicolumn{2}{c}{$\begin{array}{c}\text { Correlation } \\
\text { coefficient } r\end{array}$} & \multicolumn{2}{c}{ Significance $p$ value } \\
& Before $\varepsilon$ & After $\varepsilon^{*}$ & Before $\varepsilon$ & After $\varepsilon^{*}$ \\
\hline$f_{c}$ & -0.728 & 0.090 & 0.001 & 0.634 \\
$E_{f}$ & -0.553 & 0.158 & 0.001 & 0.405 \\
$t_{p}$ & -0.450 & 0.318 & 0.013 & 0.087 \\
$t_{f}$ & -0.636 & 0.380 & 0.001 & 0.038 \\
$t_{g}$ & -0.528 & 0.31 & 0.003 & 0.096 \\
\hline
\end{tabular}

\section{Reliability Analysis}

According to the formula put forward by the ACI code $[44,45]$, for the FRP NSM reinforcement system, the limit state function for a bonded joints strength design can be given as follows:

$$
G=R-D-L .
$$

$G$ herein is the limit state function, $R$ is the bearing capacity, $D$ is the dead load, and $L$ is the live load. In a NSM FRP reinforced concrete structure, another factor, for example, the steel reinforcement, has also contributed much to the bearing capacity. However, as this part of resistance is hard to determine [30-32], only the FRP-concrete bonded joints resistance was therefore considered as the resistance in this paper [33], but not the contribution of steel reinforcement. Hence, for the NSM FRP reinforced concrete structure design, the capacity $R$ is equivalent to the experimental value $P_{u}$ :

$$
R_{d}=P_{u}
$$

The load combination can typically be presented as follows [46]:

$$
S_{d}=1.2 D_{n}+1.6 L_{n} .
$$

$S_{d}$ herein is the design load, and $D_{n}$ and $L_{n}$ are the nominal dead load and live load, respectively. From the perspective of design, the nominal load is associated with the resistance. As a result, the nominal load can be represented by the resistance $[36,47]$ :

$$
S_{d}=\varphi \times P_{u}^{c},
$$

where $\varphi$ herein is the reduction factor for getting an appropriate reliability index $[48,49]$. With no model uncertainty factor, the value of reduction factor will vary from 0.2 to 0.8 in different models [40]. However, by calibrating the model uncertainties, we could acquire a uniform value of reduction factor [34-37]. In this paper, for achieving an appropriate reliability index $\beta$ (about 3.00), the value of the reduction factor $\varphi$ was set uniformly as 0.6 . Considering that the NSM FRP reinforcement system may be applied in different loading conditions, the live-to-dead load ratio $\eta=L_{n} / D_{n}$ was set as $0.50,0.75,1.00,1.25$, and 1.50 , respectively. 


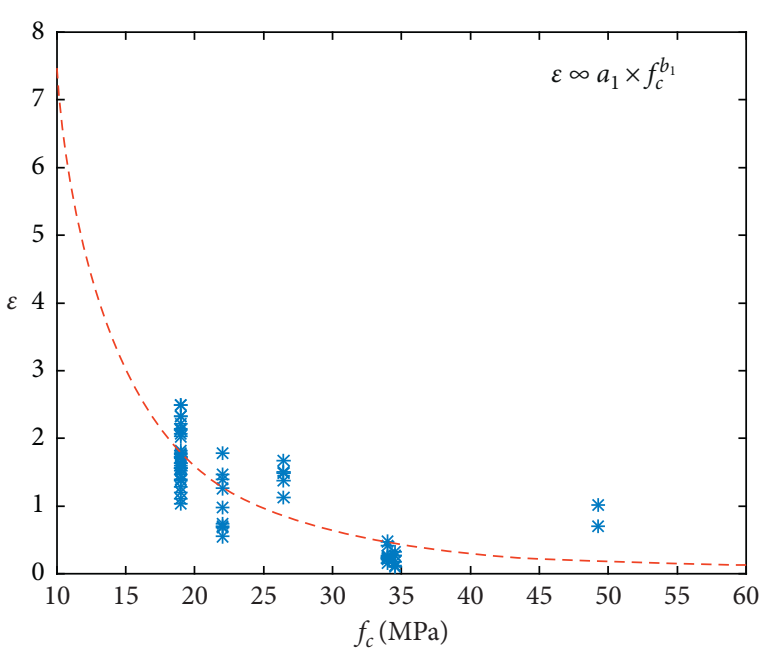

(a)

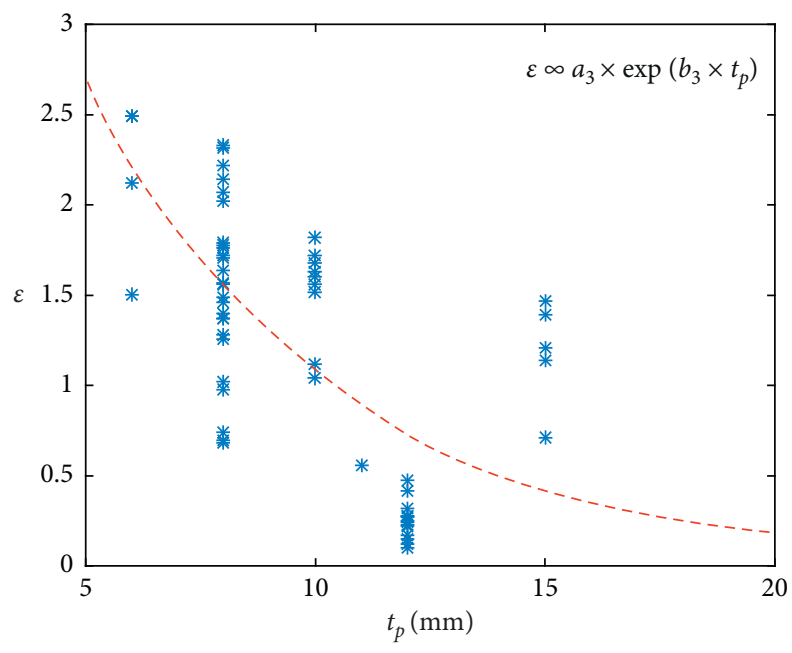

(c)

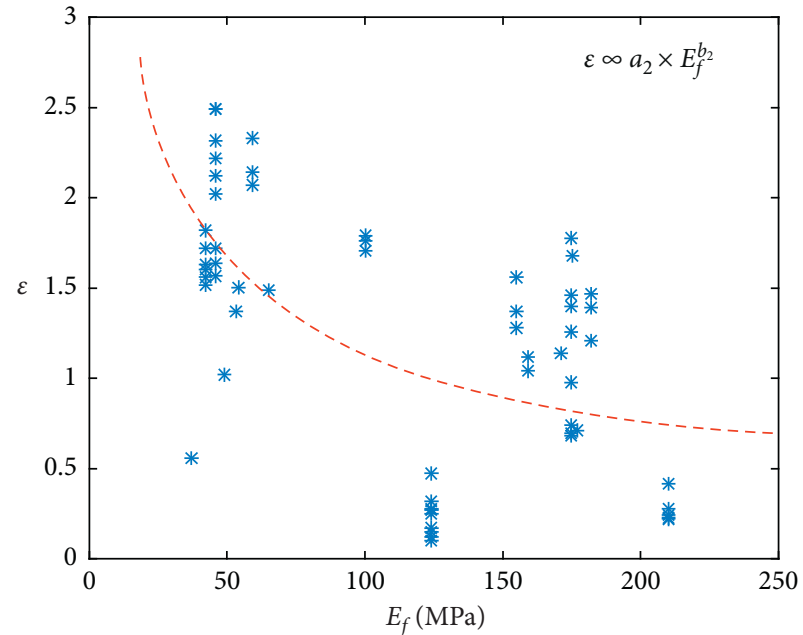

(b)

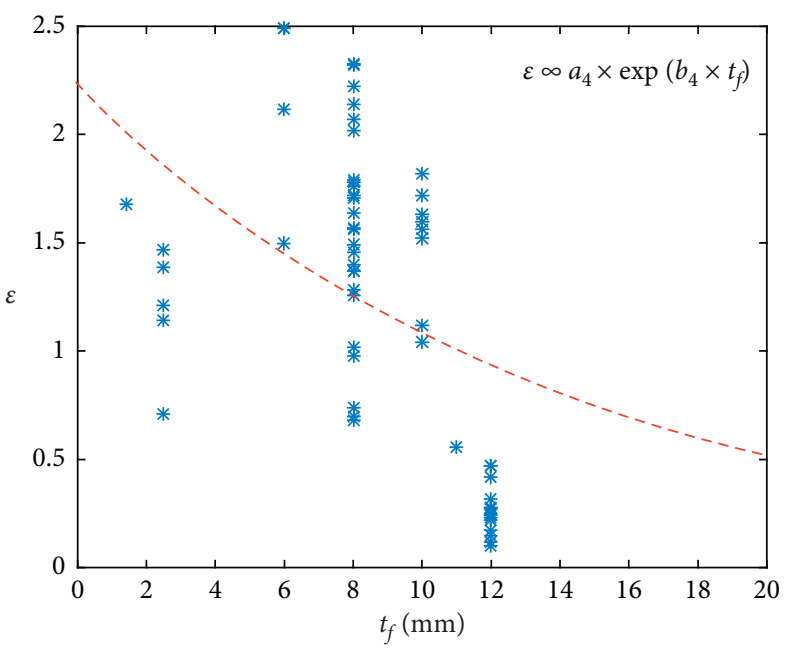

(d)

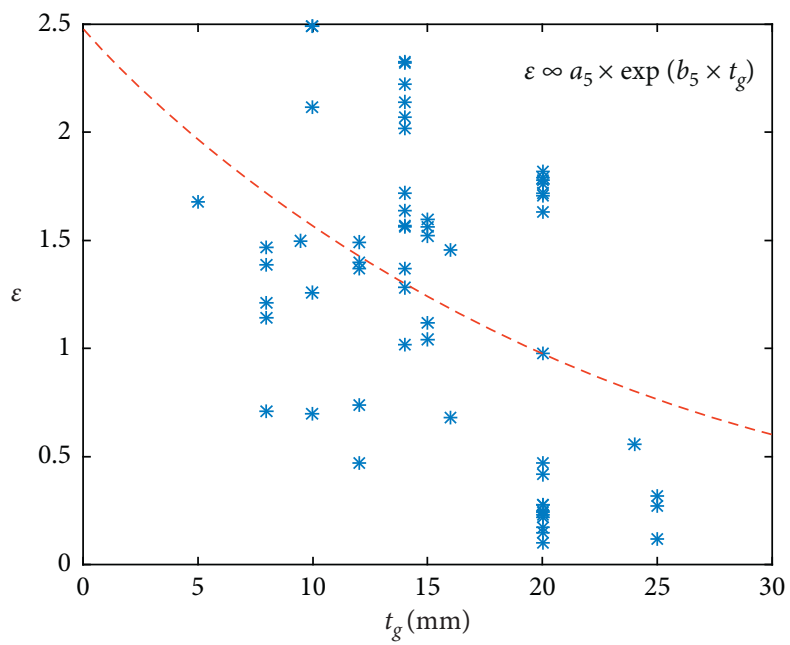

(e)

FIGURE 7: Fitting function graph: (a) concrete compression strength, (b) FRP modulus of elasticity, (c) FRP height, (d) FRP thickness, and (e) groove width. 
TABLE 13: Coefficients in the regression function $f$ for the three models.

\begin{tabular}{lccc}
\hline Coefficients & AM Model & Zhang Model & SR Model \\
\hline$b_{0}$ & 7.494 & 7.389 & 7.686 \\
$b_{1}$ & -1.245 & -1.256 & -1.036 \\
$b_{2}$ & -0.327 & -0.331 & -0.364 \\
$b_{3}$ & -0.090 & -0.087 & -0.114 \\
$b_{4}$ & -0.150 & -0.154 & -0.140 \\
$b_{5}$ & 0.003 & 0.003 & -0.005 \\
$R^{2}$ & 0.854 & 0.858 & 0.840 \\
\hline
\end{tabular}

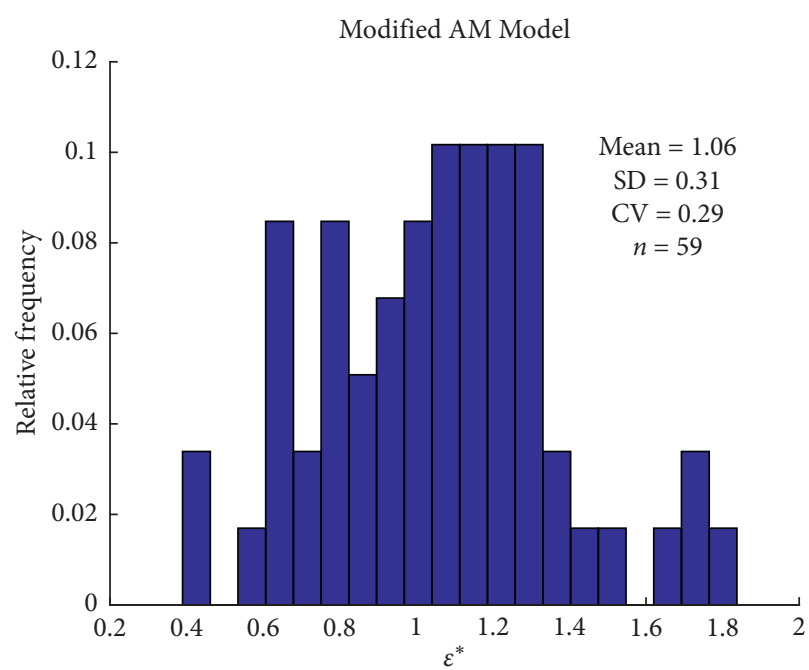

Histogram $\varepsilon^{*}$

(a)

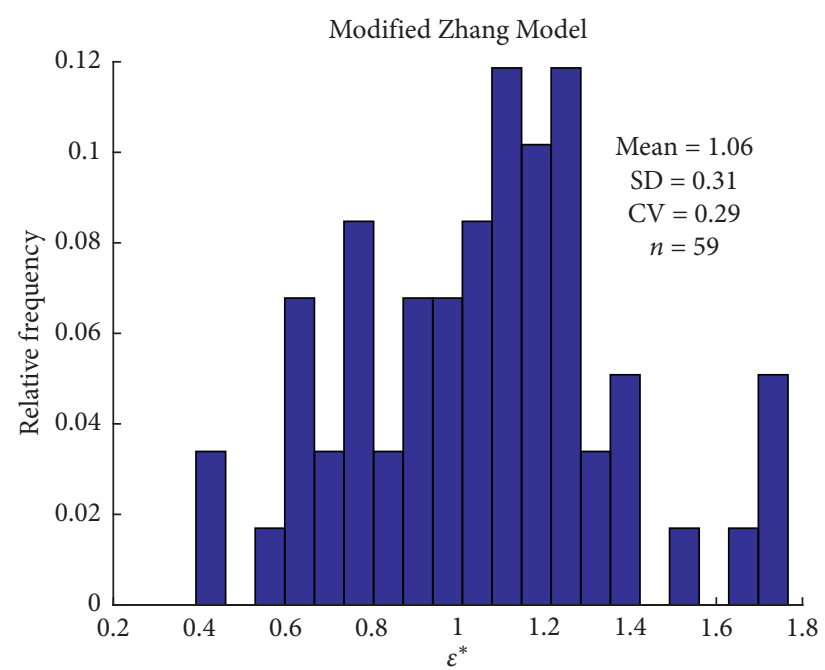

Histogram $\varepsilon^{*}$

(b)

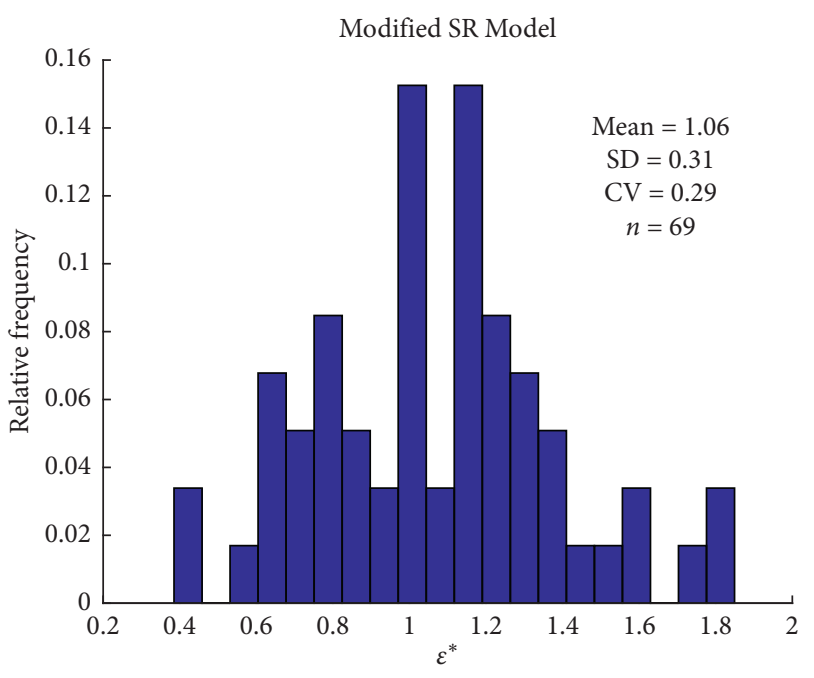

Histogram $\varepsilon^{*}$

(c)

Figure 8: Histogram of $\varepsilon^{*}$ for each modified model: (a) AM Model, (b) Zhang Model, and (c) SR Model.

Obviously, the five design parameters (i.e., $f_{c}, E_{f}, t_{p}, t_{f}$, and $t_{g}$ ) were the main influence factors in the reliability analysis. In Table 14, two groups of commonly used nominal parameters (A and B) were included for reliability analysis [50].
These two groups of parameters were from the literature review and were frequently used in the NSM FRP-concrete bonded joints reliability analysis. A set of groove width $t_{g}$ was selected from the references and experiments (i.e., 21.3, 


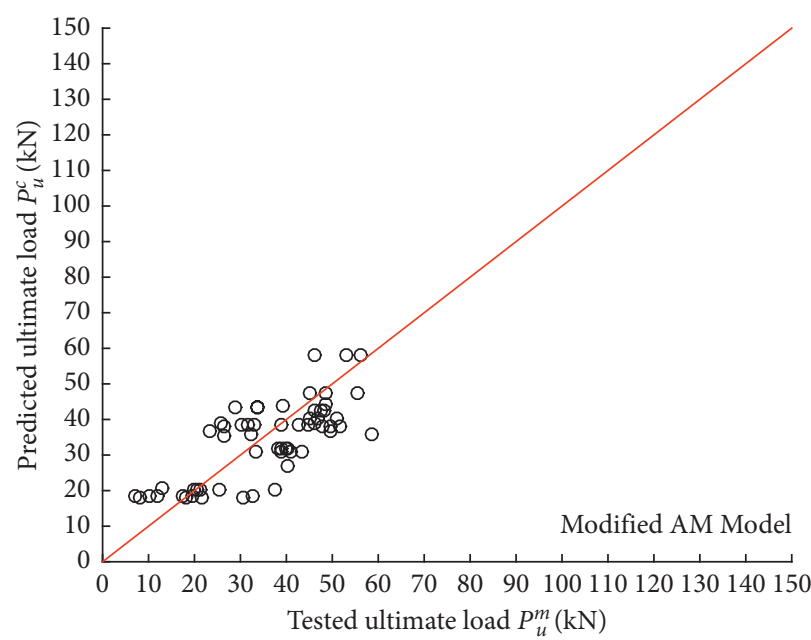

(a)

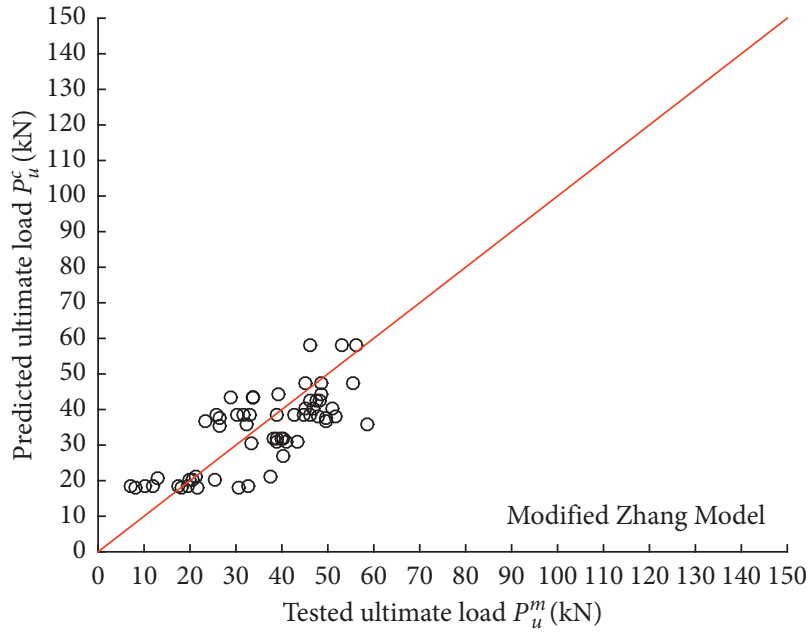

(b)

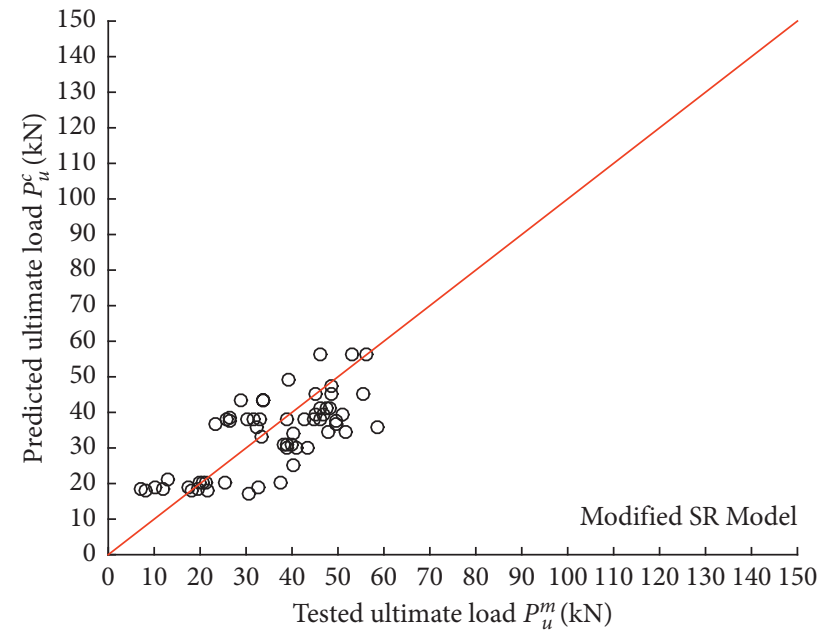

(c)

Figure 9: Comparison between the calculated value and the experimental value for the three modified models under adhesive-concrete interface failure mode: (a) AM Model, (b) Zhang Model, and (c) SR Model.

TABLE 14: Two groups of nominal parameters for the reliability analysis.

\begin{tabular}{lccc}
\hline Design parameter & $\begin{array}{c}\text { Nominal } \\
\text { value A }\end{array}$ & $\begin{array}{c}\text { Nominal } \\
\text { value B }\end{array}$ & Reference \\
\hline$f_{c}(\mathrm{MPa})$ & 27.56 & 41.3 & {$[35,36]$} \\
$E_{f}(\mathrm{GPa})$ & 52 & 165 & {$[37]$} \\
$t_{p}(\mathrm{~mm})$ & 4 & 8 & {$[35]$} \\
$t_{f}(\mathrm{~mm})$ & 8 & 12 & 9 \\
$t_{g}(\mathrm{~mm})$ & 19 & Equation $(9)$ & [50], measured date \\
$D(\mathrm{kN})$ & Equation $(9)$ & Equation $(9)$ & Galambos et al. [51] \\
$L(\mathrm{kN})$ & Equation $(9)$ & Galambos et al. [51] \\
\hline
\end{tabular}

$22.33,21.87,23.19,20.53,21.57,19.53,20.30,19.77,19.67$, 19.80 , and 22.97). The nominal $t_{g}$ was set to 19 based on the $95 \%$ probability of these values. Each of the other four design parameters (i.e., $f_{c}, E_{f}, t_{p}$, and $t_{f}$ ) was selected from one of the two groups (A and $\mathrm{B}$ ). Thus, a sample space was generated by the five design parameters, with a sample size of $1 \times 2 \times 2 \times 2 \times 2=16$. Taking each of the five $\eta$ (i.e., $0.50,0.75$,
$1.00,1.25$, and 1.50$)$ into account, we had $16 \times 5=80$ cases of reliability analysis. For every case, JC method was applied for the calculation of the reliability index $\beta$ [51-53].

Table 15 lists out three groups of reliability index $\beta$ calculated in 16 design cases. In group 1, model uncertainty factor was not taken into account. In group 2, model uncertainty factor was considered, but its systematic 
Table 15: Reliability index of 16 cases for AM Model.

\begin{tabular}{lccc}
\hline Case no. & $\begin{array}{c}\text { Group 1: without considering the model } \\
\text { uncertainty factor }\end{array}$ & $\begin{array}{c}\text { Group 2: with the unmodified model } \\
\text { uncertainty factor considered }\end{array}$ & $\begin{array}{c}\text { Group 3: with the modified model } \\
\text { uncertainty factor considered }\end{array}$ \\
\hline 1 & 2.58 & 1.53 & 3.15 \\
2 & 3.56 & 1.62 & 3.05 \\
3 & 4.82 & 2.36 & 2.98 \\
4 & 3.43 & 2.47 & 3.12 \\
5 & 0.78 & 1.64 & 3.48 \\
6 & 1.39 & 1.35 & 3.23 \\
7 & 3.47 & 2.94 & 3.78 \\
8 & 1.09 & 3.08 & 3.09 \\
9 & 6.62 & 1.51 & 2.95 \\
10 & 4.22 & 1.73 & 2.91 \\
11 & 2.45 & 1.61 & 3.96 \\
12 & 4.58 & 1.93 & 4.03 \\
13 & 5.12 & 1.54 & 3.26 \\
14 & 3.27 & 1.26 & 3.01 \\
15 & 4.40 & 3.13 & 2.87 \\
16 & 5.03 & 2.98 & 2.95 \\
Average & 3.55 & 2.04 & 3.27 \\
CV of $\beta$ & 0.44 & 0.32 & 0.11 \\
\hline
\end{tabular}

dependence being not eliminated (abbreviated as unmodified model). In group 3, the model uncertainty factor was considered, as well as its systematic dependence being eliminated (abbreviated as modified model).

Take the AM model as an example, with the live-to-dead load ratio $\eta$ at 1.00 , the calculated reliability index $\beta$ in 16 design cases is listed in Table $15[6,38]$. In group 1 (no model uncertainty factor), the calculated reliability index $\beta$ had an average value of 3.5 , which was the highest among the three groups. In group 2 (unmodified model) and group 3 (modified model), the average calculated reliability index $\beta$ decreased to 2.04 and 3.27 , respectively. In group 3 (modified model), the $\mathrm{CV}$ of $\beta$ has a lowest value of 0.11 , which was clearly less than the other two groups (0.32 and 0.44 ).

Generally, when the uncertainty is significantly underestimated, the reliability of design considering no model uncertainty factor is very unsafe $[29,43]$. Our result also indicated that very different reliability did exist in the same design case, which is due to the systematic correlation of $\varepsilon$. While practically, the same input parameters leading to quite different output reliability levels are unreasonable [42]. In summary, by eliminating the systematic correlation of $\mathcal{E}$, all the problems above can get effective solutions.

\section{Conclusions}

Some prediction models have been proposed for NSM FRPconcrete bonded joints strength. Model uncertainty inevitably does exit due to limited experimental data, incomplete research parameters, and idealized calculation method. A method of model calibration for these prediction models is presented in this study. The main conclusions were summarized as follows:

(1) A total of 246 pullout test data were collected to calibrate three selected prediction models. The model uncertainty factor was defined to quantitatively evaluate the uncertainties in a model. By using the Spearman correlation analysis, the model uncertainty factor calculated by a prediction model was checked for randomness and was proved to have a strong dependency on the design parameters.

(2) A multiple regression analysis was applied and a regression equation was established to reduce the value of $\mathrm{CV}$ for the model uncertainty factor. The systematical dependence of the model uncertainty factor on design parameters was then eliminated, and the residual factor after regression was checked for randomness. After modification, the model uncertainty factors of the three selected models have become reasonable random variables which followed the logarithmic normal distribution.

(3) For different NSM FRP bonded joints strength models, the model uncertainties can be brought to the same level after model modification. The model uncertainty factor after modification was appreciated for its merit by performing a reliability analysis using the JC method, and the calibration significantly increased the accuracy of the prediction models.

This study has widened and deepened the knowledge of the NSM FRP interfacial bonded joints strength prediction models and is desirable for guidelines to standardize the calibration of model uncertainties.

\section{Data Availability}

Data in this article used to support this study are currently under embargo while the research findings are commercialized. Requests for data will be considered 6 months after the publication of this article by the corresponding author.

\section{Conflicts of Interest}

The authors declare that they have no conflicts of interest regarding this work. 


\section{Acknowledgments}

This work was supported by the National Natural Science Foundation of China (Project no. 51608137).

\section{References}

[1] T. Hassan and S. Rizkalla, "Investigation of bond in concrete structures strengthened with near surface mounted carbon fiber reinforced polymer strips," Journal of Composites for Construction, vol. 7, no. 3, pp. 248-257, 2003.

[2] R. El-Hacha and S. H. Rizkalla, "Near-surface-mounted fiberreinforced polymer reinforcements for flexural strengthening of concrete structures," ACI Structural Journal, vol. 101, no. 5, pp. 717-726, 2004.

[3] V. Turco, N. Galati, L. De Lorenzis et al., "Bond between near surface mounted FRP rods and masonry in structural strengthening," in Proceedings of the Advancing with Composites, pp. 7-9, Plast, Russia, 2003.

[4] L. De Lorenzis and J. G. Teng, "Near-surface mounted FRP reinforcement: an emerging technique for strengthening structures," Composites Part B: Engineering, vol. 38, no. 2, pp. 119-143, 2007.

[5] D. Van Gemert, "Force transfer in epoxy bonded steel/concrete joints," International Journal of Adhesion and Adhesives, vol. 1, no. 2, pp. 67-72, 1980.

[6] F. Al-Mahmoud, A. Castel, R. François, and C. Tourneur, "Anchorage and tension-stiffening effect between near-surface-mounted CFRP rods and concrete," Cement and Concrete Composites, vol. 33, no. 2, pp. 346-352, 2011.

[7] H. Yoshizawa, "Analysis of debonding fracture properties of CFS strengthened RC member subject to tension: non-metallic (FRP) reinforcement for concrete structures," in Proceedingsof the 3rd International Symposium, pp. 287-294, The JapanConcrete Institute, Brno, Czech Republic, January 1997.

[8] S. S. Zhang, "Bond strength model for near-surface mounted (NSM) FRP bonded joints: effect of concrete edge distance," Composite Structures, vol. 201, pp. 664-675, 2018.

[9] J.-J. Zeng, W.-Y. Gao, Z.-J. Duan, Y.-L. Bai, Y.-C. Guo, and L.-J. Ouyang, "Axial compressive behavior of polyethylene terephthalate/carbon FRP-confined seawater sea-sand concrete in circular columns," Construction and Building Materials, vol. 234, p. 117383, 2020.

[10] Z. Yang, A. Liu, J. Yang, J. Fu, and B. Yang, "Dynamic buckling of functionally graded graphene nanoplatelets reinforced composite shallow arches under a step central point load," Journal of Sound and Vibration, vol. 465, p. 115019, 2020.

[11] Y.-F. Wu and C. Jiang, "Quantification of bond-slip relationship for externally bonded FRP-to-concrete joints," Journal of Composites for Construction, vol. 17, no. 5, pp. 673-686, 2013.

[12] K. Nakaba, T. Kanakubo, T. Furuta et al., "Bond behavior between fiber-reinforced polymer laminates and concrete," ACI Structural Journal, vol. 98, no. 3, pp. 359-367, 2001.

[13] L. De Lorenzis, A. Rizzo, and A. La Tegola, "A modified pullout test for bond of near-surface mounted FRP rods in concrete," Composites Part B: Engineering, vol. 33, no. 8, pp. 589-603, 2002.

[14] T. Hassan and S. Rizkalla, "Bond mechanism of NSM FRP bars for flexural strengthening of concrete structures," $A C I$ Structural Journal, vol. 101, no. 6, pp. 830-839, 2004.

[15] D. J. Oehlers, M. Haskett, C. Wu, and R. Seracino, "Embedding NSM FRP plates for improved IC debonding resistance," Journal of Composites for Construction, vol. 12, no. 6, pp. 635-642, 2008.

[16] R. Seracino, N. M. Jones, M. S. Ali, M. W. Page, and D. J. Oehlers, "Bond strength of near-surface mounted FRP strip-to-concrete joints," Journal of Composites for Construction, vol. 11, no. 4, pp. 401-409, 2007.

[17] X. Z. Lu, J. G. Teng, L. P. Ye, and J. J. Jiang, "Bond-slip models for FRP sheets/plates bonded to concrete," Engineering Structures, vol. 27, no. 6, pp. 920-937, 2005.

[18] Y.-F. Wu, X.-S. Xu, J.-B. Sun, and C. Jiang, "Analytical solution for the bond strength of externally bonded reinforcement," Composite Structures, vol. 94, no. 11, pp. 3232-3239, 2012.

[19] R. Seracino, M. R. Raizal Saifulnaz, and D. J. Oehlers, "Generic debonding resistance of EB and NSM plate-to-concrete joints," Journal of Composites for Construction, vol. 11, no. 1, pp. 62-70, 2007.

[20] M. S. M. Ali, D. J. Oehlers, M. C. Griffith, and R. Seracino, "Interfacial stress transfer of near surface-mounted FRP-toconcrete joints," Engineering Structures, vol. 30, no. 7, pp. 1861-1868, 2008.

[21] S. S. Zhang, J. G. Teng, and T. Yu, "Bond-slip model for CFRP strips near-surface mounted to concrete," Engineering Structures, vol. 56, pp. 945-953, 2013.

[22] J. F. Chen and J. G. Teng, "Anchorage strength models for FRP and steel plates bonded to concrete," Journal of Structural Engineering, vol. 127, no. 7, pp. 784-791, 2001.

[23] N. T. K. Al-Saadi and R. Al-Mahaidi, "Modelling of NSM CFRP strips embedded in concrete using lap shear tests with epoxy adhesive," Composite Structures, vol. 153, pp. 662-672, 2016.

[24] D. Novidis, S. J. Pantazopoulou, and E. Tentolouris, "Experimental study of bond of NSM-FRP reinforcement," Construction and Building Materials, vol. 21, no. 8, pp. 1760-1770, 2007.

[25] J. G. Teng, J. F. Chen, S. T. Smith et al., FRP: Strengthened RC Structures, Wiley, UK, 2002, ISBN: 978-0-471-48706-7.

[26] J. Yao, J. G. Teng, and J. F. Chen, "Experimental study on FRPto-concrete bonded joints," Composites Part B: Engineering, vol. 36, no. 2, pp. 99-113, 2005.

[27] Z. Wu, H. Yuan, and H. Niu, "Stress transfer and fracture propagation in different kinds of adhesive joints," Journal of Engineering Mechanics, vol. 128, no. 5, pp. 562-573, 2002.

[28] J. P. Lin and Y. F. Wu, "Numerical analysis of interfacial bond behavior of externally bonded FRP-to-concrete joints," Journal of Composites for Construction, vol. 20, no. 5, Article ID 04016028, 2016.

[29] A. Bilotta, F. Ceroni, M. Di Ludovico, E. Nigro, M. Pecce, and G. Manfredi, "Bond efficiency of EBR and NSM FRP systems for strengthening concrete members," Journal of Composites for Construction, vol. 15, no. 5, pp. 757-772, 2011.

[30] A. Bilotta, F. Ceroni, E. Nigro, and M. Pecce, "Strain assessment for the design of NSM FRP systems for the strengthening of RC members," Construction and Building Materials, vol. 69, pp. 143-158, 2014.

[31] A. Bilotta, F. Ceroni, J. A. O. Barros et al., "Bond of NSM FRPstrengthened concrete: round robin test initiative," Journal of Composites for Construction, vol. 20, no. 1, Article ID 04015026, 2016.

[32] D. G. Novidis and S. J. Pantazopoulou, "Bond tests of short NSM-FRP and steel bar anchorages," Journal of Composites for Construction, vol. 12, no. 3, pp. 323-333, 2008.

[33] X. Yan, B. Miller, A. Nanni et al., "Characterization of CFRP rods used as near surface mounted reinforcement," in 
Proceedings of the 8th International Conference on Structural Faults and Repair, pp. 1-12, London, UK, 1999.

[34] A. Palmieri, S. Matthys, and L. Taerwe, "Double bond shear tests on NSM FRP strengthened members," in Proceedings of the 6th international conference on FRP composites in civil engineering (CICE-2012), pp. 1-8, Rome, Italy, June 2012.

[35] R. Capozucca, "Analysis of bond-slip effects in RC beams strengthened with NSM CFRP rods," Composite Structures, vol. 102, pp. 110-123, 2013.

[36] D. Lee, L. Cheng, and J. Yan-Gee Hui, "Bond characteristics of various NSM FRP reinforcements in concrete," Journal of Composites for Construction, vol. 17, no. 1, pp. 117-129, 2013.

[37] S. M. Soliman, E. El-Salakawy, and B. Benmokrane, "Bond performance of near-surface-mounted FRP bars," Journal of Composites for Construction, vol. 15, no. 1, pp. 103-111, 2010.

[38] K.-K. Phoon and F. H. Kulhawy, "Characterisation of model uncertainties for laterally loaded rigid drilled shafts," Géotechnique, vol. 55, no. 1, pp. 45-54, 2005.

[39] C. Chen, X. Li, D. Zhao et al., "Mechanism of surface preparation on FRP-Concrete bond performance: a quantitative study," Composites Part B: Engineering, vol. 163, pp. 193-206, 2019.

[40] J. Shi, Z. Wu, X. Wang, and M. Noori, "Reliability analysis of intermediate crack-induced debonding failure in FRPstrengthened concrete members," Structure and Infrastructure Engineering, vol. 11, no. 12, pp. 1651-1671, 2015.

[41] D. M. Zhang, K. K. Phoon, H. W. Huang, and Q. F. Hu, "Characterization of model uncertainty for cantilever deflections in undrained clay," Journal of Geotechnical and Geoenvironmental Engineering, vol. 141, no. 1, Article ID 04014088, 2014.

[42] G. T. Kung, C. H. Juang, E. C. Hsiao, and Y. M. Hashash, "Simplified model for wall deflection and ground-surface settlement caused by braced excavation in clays," Journal of Geotechnical and Geoenvironmental Engineering, vol. 133, no. 6, pp. 731-747, 2007.

[43] C. Tang, K. K. Phoon, L. Zhang et al., "Model uncertainty for predicting the bearing capacity of sand overlying clay," International Journal of Geomechanics, vol. 17, no. 7, Article ID 04017015, 2017.

[44] N. Wang, B. R. Ellingwood, and A.-H. Zureick, "Reliabilitybased evaluation of flexural members strengthened with externally bonded fiber-reinforced polymer composites," Journal of Structural Engineering, vol. 136, no. 9, pp. 1151-1160, 2010.

[45] C. Chen, X. Li, X. Wang et al., "Effect of transverse groove on bond behavior of FRP-concrete interface: experimental study, image analysis and design," Composites Part B: Engineering, vol. 161, pp. 205-219, 2019.

[46] C. Chen, L. Sui, F. Xing, D. Li, Y. Zhou, and P. Li, "Predicting bond behavior of HB FRP strengthened concrete structures subjected to different confining effects," Composite Structures, vol. 187, pp. 212-225, 2018.

[47] Z. Yang, Y. Huang, A. Liu, J. Fu, and D. Wu, "Nonlinear inplane buckling of fixed shallow functionally graded graphene reinforced composite arches subjected to mechanical and thermal loading," Applied Mathematical Modelling, vol. 70, pp. 315-327, 2019.

[48] I. A. Sharaky, L. Torres, M. Baena, and C. Miàs, "An experimental study of different factors affecting the bond of NSM FRP bars in concrete," Composite Structures, vol. 99, pp. 350-365, 2013.

[49] L. Torres, I. A. Sharaky, C. Barris, and M. Baena, "Experimental study of the influence of adhesive properties and bond length on the bond behaviour of NSM FRP bars in concrete," Journal of Civil Engineering and Management, vol. 22, no. 6, pp. 808-817, 2016.

[50] R. A. Atadero and V. M. Karbhari, "Calibration of resistance factors for reliability based design of externally-bonded FRP composites," Composites Part B: Engineering, vol. 39, no. 4, pp. 665-679, 2008.

[51] T. V. Galambos, B. Ellingwood, J. G. MacGregor et al., "Probability based load criteria: assessment of current design practice," Journal of the Structural Division, vol. 108, no. 5, pp. 959-977, 1982.

[52] A. M. Okeil, A. Belarbi, and D. A. Kuchma, "Reliability assessment of FRP-strengthened concrete bridge girders in shear," Journal of Composites for Construction, vol. 17, no. 1, pp. 91-100, 2012.

[53] A. S. Nowak and M. M. Szerszen, "Calibration of design code for buildings (ACI 318): Part 1-Statistical models for resistance," ACI Structural Journal, vol. 100, no. 3, pp. 377-382, 2003. 